\section{P34 RESPIRATORY TEAM LEADING SECONDARY CARE STOP SMOKING SERVICE}

doi:10.1136/thoraxjnl-2012-202678.175

W Preston, K Hennessy, E Williams. George Eliot Hospital, Nuneaton, Warwickshire

There are over a billion smokers in the world and tobacco addiction is one of the biggest health treats for the world. Smoking tobacco kills half of its users and is estimated to cause up to one billion deaths in the $21^{\text {st }}$ century (WHO, 2010). There is a public health drive to provide behavioural and medication support to reduce the amount of current smokers and prevent future smokers. Respiratory clinicians have an opportunity to lead change and facilitate services closer to patients; smoke cessation is the key evidence based treatment for COPD that will delay progression of disease (NICE, 2010). $15 \%$ of smokers will be diagnosed with COPD and alters the immune system; there is a 2.5 increased risk of contracting pneumonia, quadrupled risk of contracting tuberculosis (Bernhard, 2011).

This case study identifies how a respiratory team have implemented a secondary care stop smoking service lead by a BTS Stop Smoking Champion. The service design is discussed, lessons learnt and results. An innovative model attracts tariff payment for in reach into schools, colleges and workplaces which in turn funds the inpatient service.

The service has been operational for 24 months and has treated over 700 patients. Respiratory nurses and AHP's are fully qualified advisers and facilitate provision with the help of a full time coordinator. Support is available on wards and in outpatient with follow up for at least 12 weeks, nicotine replacement therapy available for inpatients 24 hours per day. All pre-op patients receive carbon monoxide testing with an opt our referral system. Referral systems in place from $\mathrm{A} / \mathrm{E}$ to outpatients.

Evaluation has shown an average quit rate of $50 \%$; $65 \%$ in COPD clinics with COPD CNS advisor. 14-18 year old complex smokers $-20 \%$ quit rate and $85 \%$ in work place (routine and manual workers). NHS staff quit attempts have been consistently high (50\%) with family groups also facilitated (80\%).

To conclude respiratory staff leading on stop smoking services has been beneficial and rewarding; implementation enhanced by credibility and status of BTS role.

\section{P35 A PHYSIOLOGIST-LED INTERSTITIAL LUNG DISEASE FOLLOW UP SERVICE: EXPERIENCES AND OUTCOMES IN A UK DISTRICT GENERAL HOSPITAL}

doi:10.1136/thoraxjnl-2012-202678.176

MG Jones, K Butterfield, W McConnell. Dorset County Hospital, Dorchester, Dorset

Introduction and Objectives A proportion of patients with interstitial lung disease (ILD) maintain disease stability but require ongoing physiological and symptomatic monitoring. With increasing service demands and targets to reduce the proportion of follow up appointments, new approaches to use physician time efficiently whilst ensuring patient safety are required.

In 2006, under the supervision of a Consultant Respiratory Physician, a Physiologist Led ILD service was established in our hospital. Based on the clinical decision of the physician, patients with stable ILD at follow up are transferred for physiologist led follow up for ongoing observation. All patients attend for pulmonary function tests under the supervision of a physiologist at an interval determined by the physician. At this visit a patient symptom questionnaire is completed, and, if requested by the physician, a chest radiograph is performed. The information is subsequently reviewed by the physician who determines whether ongoing physiologist led follow up, further physician input, or discharge from follow up is required.

The Aim of this study was to retrospectively review service demand and patient outcomes over a 6 year period.
Methods Retrospective database and case review of all patients transferred by one respiratory consultant for physiologist led follow up from January 2006 until December 2011

Results 106 patients were transferred for physiologist led follow up. Mean age at commencement of follow up was 71.2.29 patients were stable throughout follow up and discharged (mean number of visits per discharged patient 2.46). 8 patients required physician input based on change in symptoms or physiological parameters. 6 of these patients were diagnosed with progression of ILD and 3 commenced on treatment. 2 subsequently died from ILD. No patient died from ILD whilst under physiologist led follow up. In 201148 follow up appointments were saved from one consultant's clinic lists.

Conclusions With appropriate patient selection, physiologist-led ILD follow up provides a safe and effective service whilst reducing the demand placed on physician follow up appointments.

\section{Respiratory physiology and oxygen therapy}

\section{P36 AN ADVANCED PHYSIOLOGICAL MONITORING TOOL TO DETECT TREATMENT FAILURE IN HOSPITALISED PATIENTS WITH ACUTE EXACERBATION OF CHRONIC OBSTRUCTIVE PULMONARY DISEASE (AECOPD)}

doi:10.1136/thoraxjnl-2012-202678.177

'ES Suh, 'S Mandal, 'MC Ramsay, ${ }^{2 R}$ Harding, ${ }^{2} \mathrm{~A}$ Thompson, ${ }^{1} \mathrm{~J}$ Moxham, ${ }^{3} \mathrm{~N}$ Hart. ${ }^{1}$ Division of Asthma, Allergy and Lung Biology, King's College London, London, UK; '2Lane Fox Respiratory Unit, Guy's St. Thomas' NHS Foundation Trust, London, UK; ${ }^{3} G u y$ 's and St Thomas' NHS Foundation TrustKing's College London, National Institute Health Research Comprehensive Biomedical Research Centre, London, UK

Background Acute exacerbations of COPD are associated with significant mortality and morbidity. Hospitalised patients with AECOPD often deteriorate symptomatically despite treatment. We have developed $2^{\text {nd }}$ intercostal space parasternal EMG $\left(\mathrm{EMG}_{\text {para }}\right)$ as a measure of neural respiratory drive (NRD), with the aim of detecting clinical change in such patients. We hypothesised that change in NRD would be able to detect treatment failure in an unselected cohort of AECOPD patients.

Methods Patients with AECOPD were recruited at a central London teaching hospital within 12 hours of admission. Patients underwent $\mathrm{EMG}_{\text {para }}$, spirometry and measurement of inspiratory capacity at least daily until medically fit for discharge. Modified Borg scale was recorded with each $\mathrm{EMG}_{\text {para }}$ acquisition. We assessed improvement and deterioration by two measures: 1) the responsible medical team was asked to report any deterioration or improvement in the patients' condition during the course of admission (Leidy et al, AJRCCM 2011); and 2) 2-point changes in Borg score were recorded as representing significant deterioration or improvement in dyspnoea (Ries et al, COPD; 2005). Changes in $\mathrm{EMG}_{\text {para\%max }}$ and neural respiratory drive index $\left(\triangle \mathrm{NRDI}\right.$, where $\mathrm{NRDI}=\mathrm{EMG}_{\text {para } \% \max } \mathrm{x}$ respiratory rate) (Murphy et al, Thorax; 2011) during episodes of deterioration or improvement were analysed.

Results 65 patients were recruited. At admission, age was $71 \pm 10$ years, male $46.2 \%, \mathrm{FEV}_{1} \%$ predicted $32 \pm 15 \%(\mathrm{n}=34)$, body mass index (BMI) $25.6 \pm 7.7 \mathrm{~kg} / \mathrm{m}^{2}$, length of hospital stay 4 (IOR 2-5.75) days, admission COPD assessment tool (CAT) score 29 (IOR 25-33). There were 66(83\%) episodes of improvement and $14(17 \%)$ episodes of deterioration as defined by physician opinion. There was a difference in the change in $\mathrm{EMG}_{\text {param }}$ between episodes of improvement and deterioration $\left(\Delta \mathrm{EMG}_{\mathrm{para} \% \max }=-2.00 \%\right.$ vs $+4.99 \%, \mathrm{p}=0.01$; $\Delta \mathrm{NRDI}=-53 / \mathrm{min}$ vs $117 / \mathrm{min}, \mathrm{p}=0.02)$. There were $54(65 \%)$ episodes of improvement and $29(35 \%)$ episodes of deterioration as defined by a 2-point change on the Borg scale. Again there was a difference in neural drive measures between improvers and deteriorators $\left(\Delta \mathrm{EMG}_{\mathrm{para} \% \max }=-3.94 \% v s+2.72 \%, \mathrm{p}=0.002 ; \Delta \mathrm{NRDI}=-108 / \mathrm{min} v \mathrm{~s}\right.$ $74 / \mathrm{min}, \mathrm{p}<0.001$ ) (Figure 1) 


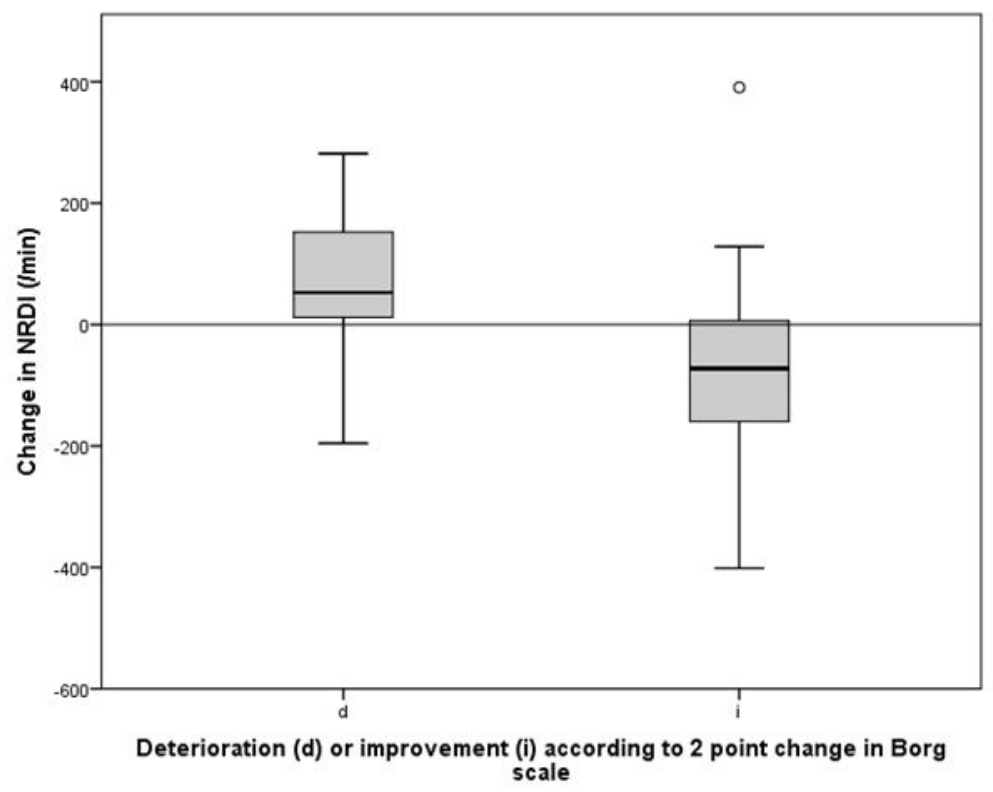

Figure 1 Change in neural respiratory drive index (NRDI) in patients whose Borg scores deteriorated by $\geq 2$ points (d), and those whose Borg scores improved by $\geq 2$ points (i). Independent $t$-test $p<0.001$

Abstract P36 Figure 1

Abstract P37 Table 1

ACCP 1974 (>=15\% baseline)

ATS/ERS 2005 (>12\% baseline and $>200 \mathrm{ml})$

ERS 1994 (>9\% predicted)

ERS 1995 (>10\% predicted)

$>12 \%$ of the baseline

$>400 \mathrm{mls}$

$>200 \mathrm{mls}$

$>12 \%$ of the predicted
M:F

1.04

1.30

0.91

0.93

1.02

2.34

1.49

0.87

${ }^{*} p<0.0001$

ns not significant

Conclusions Neural respiratory drive, as measured by parasternal muscle EMG, is effective in the detection of improvement and deterioration during $\mathrm{AECOPD}$, and demonstrates potential as a physiological biomarker to monitor clinical change.

\section{P37 WHICH BRONCHODILATOR REVERSIBILITY DEFINITION BEST AVOIDS BIAS}

doi:10.1136/thoraxjnl-2012-202678.178

${ }^{1} \mathrm{HM}$ Ward, 'BG Cooper, ${ }^{2} \mathrm{MR}$ Miller. ' University Hospitals of Birmingham, Birmingham, United Kingdom; 'Institute of Occupational and Environmental Medicine, University of Birmingham, Birmingham, United Kingdom

Introduction There is little agreement between the international respiratory societies over how bronchodilator reversibility (BDR) should be expressed. Several methods are currently being used worldwide including FEV1 change as \% of predicted, as \% from baseline, as absolute change or a combination of these methods. We explored 8 different definitions of BDR by testing the null hypothesis that the best method for expressing BDR should show no difference between the sexes.

Methods We obtained the pre and post FEV1 results for the first BDR studies using salbutamol $400 \mu \mathrm{g}$ via a spacer for white

Caucasian subjects in our laboratory database up to $11 / 1 / 12$ $[n=5369,49.6 \%$ men, mean (SD) age 50.7 (10.6) years]. The results were expressed as per the definitions of the international societies and also as their individual components if there were combined criteria: $\geq 15 \%$ change from baseline (ACCP 1974), $>12 \%$ change from baseline and >200ml (ATS 1991 and ATS/ERS 2005), >9\% change from predicted (ERS 1994), $>10 \%$ change from predicted (ERS 1995), $>400 \mathrm{ml}$ (BTS), $>12 \%$ baseline, $>200 \mathrm{ml}$, and $>12 \%$ predicted.

Results The distribution of change was right skewed with 416 subjects having a fall in FEV1 post $\mathrm{BD}$. The table shows the median baseline FEV1 and the male to female ratio for those meeting (+ve) and not meeting (-ve) the various BDR criteria. Definitions based on \% change from baseline were biased to positive results in those with smaller pre BD FEV1. BDR criteria including absolute change were biased to those with a larger FEV1 and gave a higher proportion of males with a positive BDR result. The criterion $>400 \mathrm{ml} \mathrm{FEV1} \mathrm{change}$ gave the highest male to female ratio of 2.34. Criteria including both absolute and change as \% predicted had both sex and FEV1 size bias whereas using only change as \% predicted avoided these biases.

Conclusion The most appropriate method for expressing bronchodilator response is based on change as \% of the predicted FEV1 (ERS 1994 or 1995) as it avoids sex and FEV1 size bias. 